Gupta, R. and Gregg, M. () 'Care provision fit for a warming climate', Architectural Science Review

DOI:

This document is the authors' Accepted Manuscript.

License: https://creativecommons.org/licenses/by-nc-nd/4.0

Available from RADAR: https://radar.brookes.ac.uk/radar/items/d7f12fe2-cc7f-49fc-abc1-70f34a4401f8/1/

Copyright $(\subseteq$ and Moral Rights are retained by the author(s) and/ or other copyright owners unless otherwise waved in a license stated or linked to above. A copy can be downloaded for personal non-commercial research or study, without prior permission or charge. This item cannot be reproduced or quoted extensively from without first obtaining permission in writing from the copyright holder(s). The content must not be changed in any way or sold commercially in any format or medium without the formal permission of the copyright holders. 


\section{Care provision fit for a warming climate}

Rajat Gupta and Matt Gregg

Low Carbon Building Group, School of Architecture, Oxford Brookes University,

Oxford, UK

Professor Rajat Gupta (Corresponding Author)

Low Carbon Building Group, Oxford Institute for Sustainable Development, School of Architecture, Oxford Brookes University, Headington Campus, Gipsy Lane, Oxford OX3 0BP,UK.

Tel: 01865484049

Email: rgupta@brookes.ac.uk 


\section{Care provision fit for a warming climate}

The impact of a warming climate has serious implications for older people in care facilities as they are most vulnerable to negative health effects of excessive heat. This paper uses a building simulation approach to examine the current and future risk of summertime overheating and potential adaptive response of four care and extra-care settings representing different construction, technical design and built ages across the UK. Insights from semi-structured interviews with design teams of case studies reveal their awareness and attitudes towards future-proofing design of care settings against climate change and overheating.

Modelling results demonstrate the magnitude of projected summertime overheating in care and extra-care schemes, yet there appears to be little awareness amongst designers about the risk of overheating and implementation of long-term adaptation approaches such as external shading, provision of crossventilation. Although age, location, and orientation are found to have notable effect on the magnitude of overheating, they are difficult aspects to change in existing buildings, yet they provide insights into adaptive responses with regard to retrofit, management and use of care settings. Designers also need to focus on long term planning of care settings rather than near future, to anticipate the effects of climate change on care settings.

Keywords: climate change; heatwave; overheating; care homes; dynamic thermal simulation; thermal comfort

This work was supported by Joseph Rowntree Foundation under [Grant number DER003]. 


\section{Introduction}

Within the eight years following the UK Climate Impacts Programme's release of the UK climate change projections (UKCP 2012), a larger number of research projects and papers have covered the risks (Rodrigues, Gillott, and Tetlow 2013), opportunities (Gupta, Gregg, and Williams 2015) and adaptive steps (Coley, Kershaw, and Eames 2012; Gupta and Gregg, 2012) necessary to reduce the health and comfort risk and energy impact of climate change on domestic and non-domestic buildings. Care and extra-care homes are in a unique position representing both domestic and non-domestic conditions. In addition, they also house some of the most vulnerable citizens of a country's population (Kovats, Johnson, and Griffith 2006; Fouillet et al. 2006). In particular, the older generation's vulnerability to temperature extremes, including excessive heat (Åström, Fosberg, and Rocklöv 2011; Defra 2012), is due to physiological impairment from advanced age (Kenny et al. 2010) and a range of illnesses (PHE 2014a; Koppe et al. 2004; Gasparrini et al. 2012). With the UK's ageing population projected to continue (ONS 2014), resulting in an increase in population aged over 75 from $8 \%$ of the total population in 2012 to $13 \%$ in 2035 , overheating in buildings inhabited by generally older and more vulnerable, such as residential care and extra-care schemes, is a worthwhile area to study and prepare for climate change impact.

A care home is generally for older people with frailties (physical and cognitive), providing them with single private bedrooms but with access to communal social spaces and on-site care services with meals provided and staff on call 24 hours a day, while an extra-care scheme is designed to accommodate older people who are becoming frailer and less able, but who still require and/or desire some level of independence. Extra-care housing schemes provide varying levels of care and support; at a minimum, there will 
be some kind of on-call assistance for people in an emergency, but not necessarily a 24 hour physical presence, as is available in residential care homes. Extra-care schemes also usually provide self-contained units, consisting of a kitchen, living/dining area, bathroom and one or two bedrooms, in addition to communal social facilities. Care and extra-care housing schemes are generally hybrid building-types, simultaneously functioning as long-term residences, sometimes nursing environments, and workplaces (Walker, Brown, and Neven 2015). Current regulatory, design and business considerations of care schemes prioritize warmth when considering the thermal comfort of residents (Walker, Brown, and Neven 2015; Brown 2010; Neven, Walker, and Brown 2015).This arrangement provides a complex environment when also considering the thermal comfort needs of the active staff in addition to the vulnerable residents.

In response to the heatwave of 2003, the Heatwave Plan for England (PHE 2014b), linked to the UK Met Office (2015) Heat-Health Watch Service (HHWS) (that provides early warning of periods of high temperatures which may affect the health of the UK public) provides practical advice on how the health service sector should prepare for and deal with hot weather during and after a period of weather above the HHWS regional threshold temperatures. Despite this, there is some evidence that newbuild care and extra-care housing schemes are already too warm for occupants and are overheating (Burns 2008; Barnes et al. 2012; Lewis 2014; Guerra-Santin and Tweed 2013).

Four studies of care/extra-care buildings were reviewed for their modelling, simulation, or general adaptive response results to prepare for this research. These are Garscube Road Housing (Building Performance Evaluation programme (BPE)) (QCHA and MEARU 2015), St. Loyes ExtraCare4Exeter (Design for Future Climate programme (D4FC)) (Gale et al. 2011), British Trimmings Extra Care Home (D4FC) 
(McHugh and Keeffe, 2012), and Edge Lane, Liverpool (D4FC) (MA and OBU, 2012).

Shading: Among the D4FC projects external, shading was most effective in reducing solar gain; in the Edge Lane project, using a closing response to $100 \mathrm{~W} / \mathrm{m}^{2}$ of incident solar radiation, external shading was between two and eight times more effective than internal shading at reducing overheating hours, depending on climate period modelled. Ventilation: Though heavyweight buildings were found to be more effective in reducing overheating, they perform worse if there is not sufficient ventilation; e.g., single sided ventilation (common in the care sector) does not provide effective ventilation to avoid summertime overheating especially in heavyweight buildings. Night-time ventilation is crucial to limiting overheating. This is also demonstrated through monitoring in a non-domestic example: Gupta and Gregg (2016) and through thermal simulation in a domestic example: Gupta and Gregg (2012). However, in the BPE example, some residents had a problem with the level of road noise, security or wind when attempting night ventilation, limiting use, causing difficulty during periods of higher heat. Internal gain was also a strong contributor; combining supplemental ventilation and window ventilation particularly in kitchens was found to be important for reduction of overheating. Internal gains: All studies showed that limiting internal gains is an important adaptation strategy. In the BPE study, one bedroom was found to overheat due to a hot water cylinder in a closet adjacent to the room. Surface materials: Light coloured surfaces have the ability to reduce the impact of incident solar radiation on surfaces, thereby reducing the magnitude of heat transfer into the building. A green roof on the building can help reduce the range of temperature fluctuations in the roof structure. D4FC projects cited other literature regarding green roofs, i.e. no actual simulation or testing proved evapotranspiration benefits. All designs also considered providing external space for overheating relief. 
Within this context, this paper investigates, using dynamic thermal simulation, the impact of current and future risk of summertime overheating in two care homes and two extra-care settings and the adaptive responses which are deemed to be most effective. Insights from semi-structured interviews with design teams of case study care settings reveal their awareness and attitudes towards future climate change and overheating. The findings emphasize the importance of dynamic thermal simulation in revealing overheating risk and evaluating appropriate adaptation responses.

\section{Methodology}

A case study based approach was adopted in the study, focussing on two residential care homes and two extra-care facilities. As confirmed by Flyvbjerg (2006) a detailed examination of a single or few case examples can provide reliable information about the broader class.

The case studies are located in (A) Leeds, Yorkshire and the Humber (care home), (C) Bristol, South West England (extra-care), and in (B) Milton Keynes and (D) Reading South East England (one care home and one extra-care respectively). Table 1 outlines the key characteristics of the case studies and other important criteria considered during the selection process. In addition, refer to Gupta, Barnfield, and Gregg (2016) for more detail on the case studies and the selection process.

Table 1. Summary of characteristics of the four case study care settings.

\begin{tabular}{|l|l|l|l|l|}
\hline Category & Case Study A & Case Study B & Case Study C & Case Study D \\
\hline Region & $\begin{array}{l}\text { Yorkshire and the } \\
\text { Humber }\end{array}$ & $\begin{array}{l}\text { South East } \\
\text { England }\end{array}$ & $\begin{array}{l}\text { South West } \\
\text { England }\end{array}$ & $\begin{array}{l}\text { South East } \\
\text { England }\end{array}$ \\
\hline Location & Suburban & Rural & Suburban & Suburban \\
\hline Type of facility & $\begin{array}{l}\text { Integrated care } \\
\text { community } \\
\text { (purpose built) }\end{array}$ & $\begin{array}{l}\text { Residential care } \\
\text { home (renovated) }\end{array}$ & $\begin{array}{l}\text { Extra-care } \\
\text { (purpose built) }\end{array}$ & $\begin{array}{l}\text { Extra-care } \\
\text { (purpose built) }\end{array}$ \\
\hline Ownership & $\begin{array}{l}\text { Not-for-profit, } \\
\text { registered social } \\
\text { landlord (RSL) }\end{array}$ & Private company & $\begin{array}{l}\text { Not-for-profit } \\
\text { RSL }\end{array}$ & $\begin{array}{l}\text { Not-for-profit } \\
\text { RSL }\end{array}$ \\
\hline
\end{tabular}




\begin{tabular}{|c|c|c|c|c|}
\hline $\begin{array}{l}\text { Gross internal area } \\
\text { (GIA) } \mathrm{m}^{2}\end{array}$ & not-provided & 820 (estimated) & 4,823 & 5,500 (estimated) \\
\hline $\begin{array}{l}\text { No. of } \\
\text { beds/dwellings }\end{array}$ & $\begin{array}{l}42 \text { beds }+102- \\
\text { bed cottages }\end{array}$ & 22 beds & 50 flats & 60 flats \\
\hline $\begin{array}{l}\text { Per cent of residents } \\
\text { over } 85 \text { years }\end{array}$ & $77 \%$ & $64 \%$ & $83 \%$ & $80 \%$ \\
\hline $\begin{array}{l}\text { Constructed year of } \\
\text { facility (Building } \\
\text { regulations year) }\end{array}$ & $2005(2000)$ & Pre-1900s (N/A) & $2006(2002)$ & $2012(2006)$ \\
\hline Construction type & $\begin{array}{l}\text { Brick/stone and } \\
\text { block insulated } \\
\text { cavity; concrete } \\
\text { beam and block } \\
\text { floors }\end{array}$ & $\begin{array}{l}\text { Solid brick; } \\
\text { timber floors }\end{array}$ & $\begin{array}{l}\text { Brick and block } \\
\text { insulated } \\
\text { cavity/rendered } \\
\text { insulation with } \\
\text { block; concrete } \\
\text { beam and block } \\
\text { floors }\end{array}$ & $\begin{array}{l}\text { Steel frame with } \\
\text { insulated } \\
\text { brick/render wall } \\
\text { finish; reinforced } \\
\text { concrete slab } \\
\text { floors }\end{array}$ \\
\hline $\begin{array}{l}\text { Ventilation and/ or } \\
\text { cooling scheme }\end{array}$ & $\begin{array}{l}\text { Mixed mode: } \\
\text { Natural } \\
\text { ventilation with } \\
\text { Mechanical } \\
\text { ventilation with } \\
\text { heat recovery } \\
\text { (MVHR) in } \\
\text { residential and } \\
\text { communal kitchen } \\
\text { and sanitary areas }\end{array}$ & $\begin{array}{l}\text { Natural } \\
\text { ventilation with } \\
\text { some extract } \\
\text { ventilation in } \\
\text { communal kitchen } \\
\text { and sanitary areas }\end{array}$ & $\begin{array}{l}\text { Mixed mode: } \\
\text { Natural } \\
\text { ventilation with } \\
\text { some extract } \\
\text { ventilation in } \\
\text { residential; } \\
\text { communal kitchen } \\
\text { and sanitary areas } \\
\text { and air } \\
\text { conditioning in } \\
\text { lounge and dining }\end{array}$ & $\begin{array}{l}\text { Mixed mode: } \\
\text { Natural } \\
\text { ventilation with } \\
\text { MVHR in } \\
\text { residential, } \\
\text { communal kitchen } \\
\text { and sanitary areas } \\
\text { and air } \\
\text { conditioning in } \\
\text { office }\end{array}$ \\
\hline $\begin{array}{l}\text { Exceptional design } \\
\text { standards or } \\
\text { certification }\end{array}$ & N/A & $\begin{array}{l}\text { Listed building } \\
\text { (Grade II) }\end{array}$ & $\begin{array}{l}\text { CSH/EcoHomes } \\
\text { Good }\end{array}$ & $\begin{array}{l}\text { BREAAM } \\
\text { Excellent }\end{array}$ \\
\hline
\end{tabular}

${ }^{1}$ Note: Both care and extra-care development; however, only the care home building was studied

The impacts of current and projected climate conditions on the case studies were simulated using the dynamic thermal simulation (DTS) software suite developed by Integrated Environmental Solutions Virtual Environment (ModelIT, Apache, MacroFlo, and VistaPro). This was done to assess the magnitude of the risk of overheating in the care homes. To assess overheating risk and develop appropriate adaptation strategies, the following steps were taken:

(1) climate change projections were selected for modelling (hazard),

(2) define the environmental conditions in and surrounding the building; select spaces for each case study were modelled (exposure),

(3) information on user and behaviour collected and modelled (vulnerability),

(4) overheating and heatwave risk assessed using selected overheating metric (risk) 
(5) adaptation options are tested to arrive at potentially effective remedial measures (response)

In addition to building surveys, modelling and simulation the project also involved interviews with the building's designers with the intent to assess how effectively building design addressed overheating risks and vulnerabilities.

\section{Simulating the future climate projections}

Current condition (baseline) and future climate weather year (FWY) files are used to simulate climate impact. These weather files, created using the Weather Generator of the UK Climate Projections 2009 (UKCP09), have been obtained from a catalogue of weather files developed by the PROMETHEUS project from the University of Exeter (Eames, Kershaw, and Coley 2011).

The selection of suitable WY files for the DTS was based on four factors:

(1) Location: WY file sets are selected for their proximity to the case study locations, all within five miles of the case study with the exception of case study B which is 20 miles from the nearest weather station.

(2) Climate periods: UKCP09 provides projections for seven climate periods (30 year time periods). Three time periods have been selected to represent: Short (2030s), medium (2050s) and long term climate conditions (2080s). New buildings constructed today typically require building services replacement every 15-20 years (short term). They would have minor refurbishment after 3545 years (medium term), and major refurbishments would occur after 60-100 years (long term).

(3) Carbon emission scenarios: UKCP09 offers climate projections based on three emission scenarios; low, medium and high. The high carbon emission scenario 
has been selected, as observed emissions have been following this path (EEA, 2012). In addition, building adaptations would still be effective under the medium or low emission scenarios.

(4) Risk percentiles: UKCP09 offers climate projections based on a probabilistic approach. Of the most commonly cited probabilities, $10 \%$ (more likely to be greater than), $50 \%$ (central estimate), and $90 \%$ less likely to be greater than) (UKCP09, 2012), 50\% probability was used in the research.

The above guidelines result in four projections for each location. In summary, these are:

(1) Current conditions, i.e. baseline weather year (BWY)

(2) 2030s climate period, high emissions scenario, 50\% probability (FWY)

(3) 2050s climate period, high emissions scenario, 50\% probability (FWY)

(4) 2080s climate period, high emissions scenario, 50\% probability (FWY)

Design Summer Years (DSY) versions of each WY file is used as it represents a complete year selected from the climate period for having the third hottest period from April - September in other words a hot but not extreme summer.

\section{Modelling the care homes and the users}

For each case study, the plan involved assessing two bedrooms (in care homes), two flats (in extra-care homes), an office and the public lounge. To collect data on the case study buildings, construction drawings, and material and system specifications were collected from the owner and or architect as most buildings were constructed recently. In the case of the pre-1919 building, a renovation was planned; therefore, as-built drawings were submitted and available from the local planning office. In addition to drawings, site visits were made to complete building survey forms developed for the 
study to verify or collect additional information needed for modelling purposes. This information included, heating, air conditioning and ventilation system models, seasonal set-points, occupancy count and times, heating set-points and times, window opening patterns, and other information regarding personal shading devices, equipment or fans not found on the drawings.

\section{Assessing current and future overheating}

Gupta, Barnfield, and Gregg (2016) critically reviews the evolving understanding of overheating, thermal comfort and appropriate thresholds in the UK and the various methods for assessing overheating and health-temperature thresholds in the UK for the different sub-sectors of the building stock, particularly in the care sector. From this review, overheating and heatwave vulnerability were assessed through two primary metrics: overheating as defined by CIBSE $(2006 ; 2013)$ and vulnerability to heatwaves as defined by the Met Office (2015) and the Heatwave Plan for England (PHE 2014b). Due to the hybrid nature of care sector buildings (both residential and work places) it was considered appropriate to use both of CIBSE's static and adaptive overheating methods for assessment. To summarize the methods used to evaluate the climate impact, table 2 lists relevant details of the overheating methods used in the study which are relevant to the care sector.

Table 2. Health and comfort related overheating assessment methods.

\begin{tabular}{|l|l|l|l|l|}
\hline $\begin{array}{l}\text { Method } \\
\text { (source) }\end{array}$ & Sub-sector & $\begin{array}{l}\text { Effective } \\
\text { period }\end{array}$ & Threshold (s) & Detailed description \\
\hline \multicolumn{5}{|c|}{ Heatwave } \\
\hline $\begin{array}{l}\text { Met Office } \\
\text { Heat-Health } \\
\begin{array}{l}\text { Watch Service } \\
(2015)\end{array}\end{array}$ & $\begin{array}{l}\text { No sub-sector; } \\
\text { universally } \\
\text { applicable } \\
\text { within UK }\end{array}$ & $\begin{array}{l}\text { 1 June }-15 \\
\text { September }\end{array}$ & $\begin{array}{l}\text { Regional } \\
\text { (external temp.): } \\
\text { South east: } \\
31^{\circ} \mathrm{C} / 16^{\circ} \mathrm{C} \\
\text { South west: } \\
30^{\circ} \mathrm{C} / 15^{\circ} \mathrm{C}\end{array}$ & $\begin{array}{l}\text { External temperature trigger } \\
\text { thresholds: daytime and } \\
\text { overnight thresholds (e.g. south } \\
\left.\text { east } 31^{\circ} \mathrm{C} / 16^{\circ} \mathrm{C}\right) \text { must be met } \\
\text { for at least two consecutive days }\end{array}$ \\
\hline
\end{tabular}




\begin{tabular}{|c|c|c|c|c|}
\hline & & & $\begin{array}{l}\text { Yorkshire: } \\
29^{\circ} \mathrm{C} / 15^{\circ} \mathrm{C}\end{array}$ & \\
\hline $\begin{array}{l}\text { Public Health } \\
\text { England (PHE) } \\
\text { Heatwave Plan } \\
\text { for England } \\
\text { (2014b) }\end{array}$ & $\begin{array}{l}\text { Primarily } \\
\text { health and } \\
\text { social care but } \\
\text { can extend } \\
\text { further }\end{array}$ & $\begin{array}{l}1 \text { June }-15 \\
\text { September } \\
\text { (dependent } \\
\text { on HHWS) }\end{array}$ & $\begin{array}{l}\text { During and } \\
\text { beyond level } 2 \\
\text { alert: ensure } \\
\text { designated } \\
\text { indoor cool } \\
\text { areas remain } \\
\text { below } 26^{\circ} \mathrm{C}^{1}\end{array}$ & $\begin{array}{l}\text { Alert levels } 2 \text { ( } 60 \% \text { heatwave } \\
\text { forecasted) and } 3 \text { (heatwave } \\
\text { action) are implemented in } \\
\text { preparation for and during } \\
\text { heatwave period as defined by } \\
\text { HHWS trigger thresholds. } \\
\text { Alerts result in recommended } \\
\text { actions. }\end{array}$ \\
\hline \multicolumn{5}{|c|}{ Overheating } \\
\hline $\begin{array}{l}\text { CIBSE Guide A } \\
\text { (2006) (static) }\end{array}$ & $\begin{array}{l}\text { Domestic \& } \\
\text { non-domestic } \\
\text { (free-running) }\end{array}$ & $\begin{array}{l}\text { 'Summer' } \\
\text { presumed to } \\
\text { be } 1 \text { June - } \\
31 \text { August } \\
\text { from } \\
\text { (CIBSE, } \\
2006, \text { p.2-6) }\end{array}$ & \multicolumn{2}{|c|}{$\begin{array}{l}\text { Overheating occurs when: } \\
\text { In living areas / Offices: } 1 \% \text { of occupied hours } \\
>28^{\circ} \mathrm{C} \text { indoor operative temperature. } \\
\text { In bedrooms: } 1 \% \text { of occupied hours }>26^{\circ} \mathrm{C} \text { indoor } \\
\text { operative temperature. }\end{array}$} \\
\hline $\begin{array}{l}\text { TM52 2013/ } \\
\text { CIBSE Guide A } \\
2015 \text { (based on } \\
\text { BS EN } \\
\text { 15251:2007) } \\
\text { (adaptive) }\end{array}$ & $\begin{array}{l}\text { Non-domestic } \\
\text { (free-running) }\end{array}$ & $\begin{array}{l}1 \text { June - } 31 \\
\text { August }\end{array}$ & \multicolumn{2}{|c|}{$\begin{array}{l}\text { Dynamic internal temperature threshold assessed } \\
\text { during occupied hours based on adaptation to } \\
\text { external temperatures over time. } \\
\text { Three criteria assessed: 1) hours of exceedance, 2) } \\
\text { daily weighted exceedance, and } 3 \text { ) upper limit } \\
\text { temperature. Two out of three criteria must fail for } \\
\text { the room to be assessed as 'overheated'. } \\
\text { Includes levels of occupant sensitivity (e.g. } \\
\text { category I for spaces occupied by very sensitive and } \\
\text { fragile persons). }\end{array}$} \\
\hline
\end{tabular}

${ }^{I}$ Note: though the guidance does not define a size or capacity of a cool area, for the purpose of this research, the communal spaces are considered the only viable location that should satisfy this criterion.

\section{Assessing adaptation options}

Following the review of the D4FC and BPE studies, the following adaptations were selected for assessment to mitigate or reduce risk:

- passive: green roof, reflective roof and walls, canopy cover over courtyards (where possible), green cover, external shutters, interior blinds, improved glazing, solar film, exposed thermal mass;

- semi-active: managed natural ventilation;

- active: ceiling fans 
Assessment of the effectiveness of ceiling fans is performed using the Predicted Mean Vote index (PMV) in post-simulation results analysis, where change in air velocity can be used to assess impact on thermal comfort (not currently possible in the overheating methods listed above).

\section{Results}

\section{Occurrence of overheating}

Figure 1 shows the overheating results for the case studies using the static method and table 3 shows the overheating results using the adaptive method. Though the 2030s climate period was assessed along with 2050s and 2080s, the latter are the focus of the paper due to the low occurrence of overheating in 2030s or earlier. It should be noted however, that Case $\mathrm{C}$ simulation demonstrated some overheating in the $2030 \mathrm{~s}$ and BSY. In the figures below the darker zone above $1 \%$ shows the zone of overheating, i.e. below $1 \%$ is not overheated. In the table showing the adaptive method results, where two or more criteria failed, overheating is occurring. 


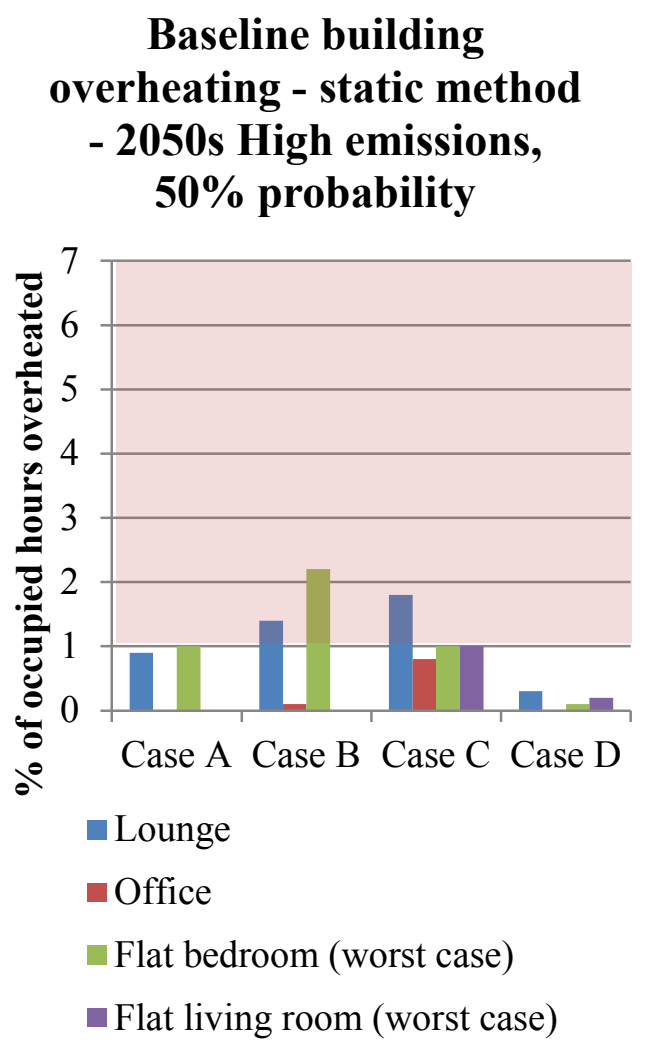

Baseline building overheating - static method

- 2080s High emissions, $50 \%$ probability

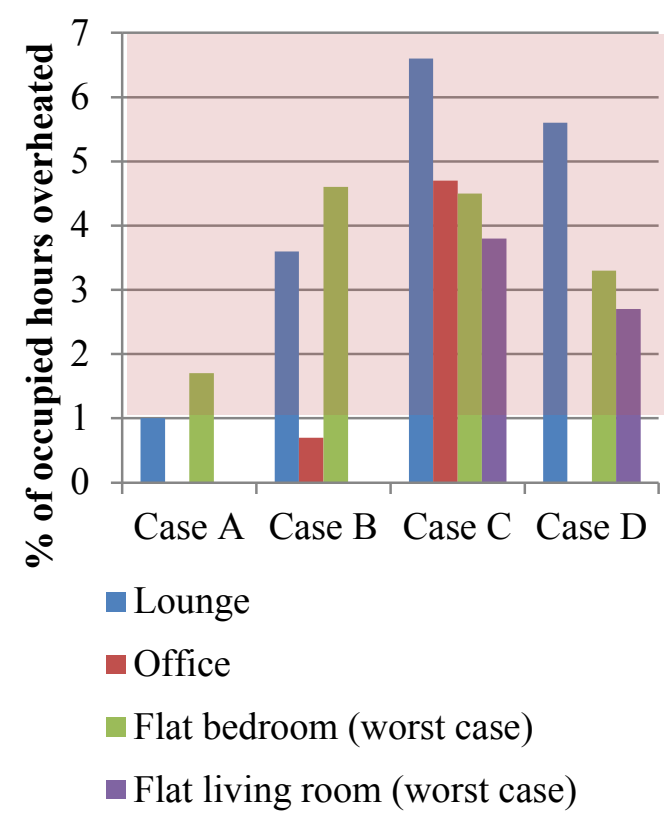

Figure 1. 2050s (left) and 2080s (right) climate period overheating results using the static method

Table 3. 2050s and 2080s climate period overheating results using the adaptive method

\begin{tabular}{|l|l|l|l|l|l|l|l|l|}
\hline & \multicolumn{2}{|c}{ Case A } & \multicolumn{2}{c|}{ Case B } & \multicolumn{2}{c|}{ Case C } & \multicolumn{3}{c|}{ Case D } \\
\hline & $\mathbf{2 0 5 0}$ & $\mathbf{2 0 8 0}$ & $\mathbf{2 0 5 0}$ & $\mathbf{2 0 8 0}$ & $\mathbf{2 0 5 0}$ & $\mathbf{2 0 8 0}$ & $\mathbf{2 0 5 0}$ & $\mathbf{2 0 8 0}$ \\
\hline Lounge & 2 & 1,2 & 1,2 & $1,2,3$ & $1,2,3$ & $1,2,3$ & - & 1,2 \\
\hline Office & - & - & - & - & - & - & - & - \\
\hline Bedroom & 2 & 2 & 2,3 & $1,2,3$ & 2 & 2 & - & - \\
\hline Living room & n/a & n/a & n/a & n/a & 2 & $1,2,3$ & - & 2 \\
\hline
\end{tabular}

Note: each number represents the criterion failed (see table 2). Where at least two criteria fail, overheating exists.

Table 4 presents the heatwave thresholds and counts for the case study locations. Note that Leeds experiences heatwaves before others (2030s and 2050s) (partially attributed to the lower threshold) but the other locations have heatwaves with much higher peak temperatures at $2080 \mathrm{~s}$. 
Table 4. Heatwave statistics for WY file projections at each location

\begin{tabular}{|c|c|c|c|c|c|}
\hline Location & $\begin{array}{l}\text { Heatwave } \\
\text { day max. } \\
\left({ }^{\circ} \mathrm{C}\right)\end{array}$ & $\begin{array}{l}\text { Heatwave } \\
\text { Night min. } \\
\left({ }^{\circ} \mathrm{C}\right)\end{array}$ & $\begin{array}{l}\text { No. of } \\
\text { heatwaves }\end{array}$ & $\begin{array}{l}\text { No. of heatwave } \\
\text { periods lasting longer } \\
\text { than } 2 \text { day min. }\end{array}$ & $\begin{array}{l}\text { No. of days } \\
\text { with temps. } \geq \\
\text { day max. }\end{array}$ \\
\hline $\begin{array}{l}\text { Leeds (Case A) } \\
\text { (current climate) }\end{array}$ & \multirow{4}{*}{29} & \multirow{4}{*}{15} & - & - & - \\
\hline $2030 \mathrm{H} 50 \%$ & & & 1 & - & 4 \\
\hline $2050 \mathrm{H} 50 \%$ & & & 4 & 2 & 8 \\
\hline $2080 \mathrm{H} 50 \%$ & & & 1 & 1 & 7 \\
\hline $\begin{array}{l}\text { MK (Bicester) (Case } \\
\text { B) (current climate) }\end{array}$ & \multirow{4}{*}{31} & \multirow{4}{*}{16} & - & - & - \\
\hline 2030 H $50 \%$ & & & - & - & 1 \\
\hline $2050 \mathrm{H} 50 \%$ & & & - & - & 1 \\
\hline 2080 H $50 \%$ & & & 2 & 1 & 10 \\
\hline $\begin{array}{l}\text { Bristol (Case C) } \\
\text { (current climate) }\end{array}$ & \multirow{4}{*}{30} & \multirow{4}{*}{15} & - & - & 2 \\
\hline 2030 H $50 \%$ & & & - & - & 1 \\
\hline $2050 \mathrm{H} 50 \%$ & & & 2 & - & 6 \\
\hline $2080 \mathrm{H} 50 \%$ & & & 6 & 3 & 26 \\
\hline $\begin{array}{l}\text { Reading (Case D) } \\
\text { (current climate) }\end{array}$ & \multirow{4}{*}{31} & \multirow{4}{*}{16} & - & - & 1 \\
\hline $2030 \mathrm{H} 50 \%$ & & & - & - & - \\
\hline $2050 \mathrm{H} 50 \%$ & & & - & - & 2 \\
\hline 2080 H $50 \%$ & & & 4 & 4 & 21 \\
\hline
\end{tabular}

\section{Adaptation measures}

From the adaptation options testing, it was concluded that the most effective passive adaptation options include shading, e.g. with shutters (allow greatest seasonal variation), reflective roofing material, thermal mass (only where applicable - Case D), and in some instances interior blinds. Figure 2 shows the effectiveness of three adaptation measures in the lounge of the case studies in the 2080s climate period using the static method. Shutters are most effective for two case studies but Case B and Case $\mathrm{C}$ are more responsive to other options. In some spaces, singular simple measures are effective in mitigating overheating risk; however, in other spaces packages of measures will be required and in some instances at 2080s climate period no (tested) combination of passive measures were effective in eliminating overheating, e.g. Case $\mathrm{C}$ lounge. 
Most effective single passive measures for lounge (2080s static method)

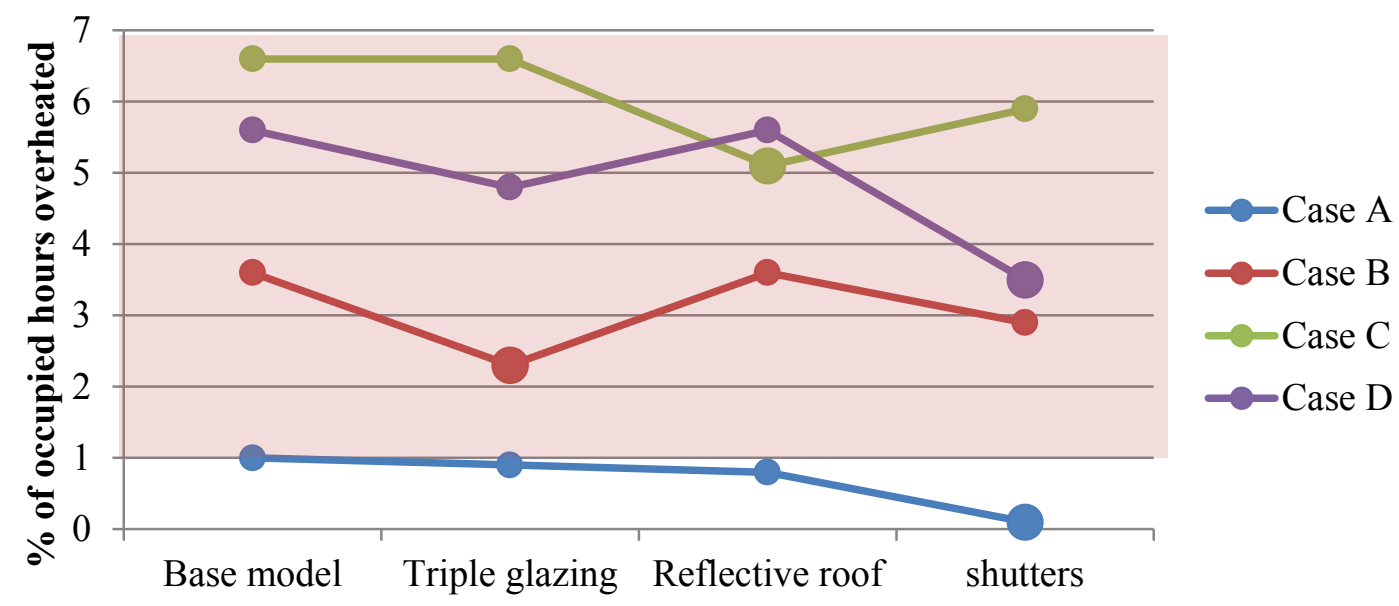

Figure 2. Most effective single passive adaptation measures for the case studies' lounges

Management of natural ventilation (ventilation dependent on external conditions) can be either passive or active depending on how it is controlled. In some cases appropriate natural ventilation management (in this study, closing windows when the external temperature is $>25^{\circ} \mathrm{C}$ ) is effective alone in eliminating overheating risk. Intelligent natural ventilation management will require carers, building managers, or building management systems to be involved in temperature monitoring, and window opening and closing management or supervision.

The building survey revealed that several residents are already using mobile electric fans as a 'quick-fix' to keep cool, wherein some cases, residents or their family members were required to provide these. Ceiling fans are an effective, low energy, and inexpensive integrated option. As an example, in Case A - First floor (FF) bedroom for all hours over $25.5^{\circ} \mathrm{C}$ between $1900-0700$ fan energy consumption can range between 0.9-1.8 $\mathrm{kWh}$ (depending on fan selection) for the entire summer. Alternatively at 24 hour occupancy this would be 3.5-7 kWh (EEC 2015). 
Figure 3 shows the impact of using fans to improve the comfort of occupants during the peak temperature period of a heatwave (2080s climate period). The 'most effective single measure' refers to the respective measures shown in figure 2. For Case $\mathrm{C}$ the internal temperature is too high for increased air velocity to improve thermal comfort. For the other case studies the addition of a fan is helpful but the case studies are unable to satisfy PMV for Category I (PMV =0.2). Again, integrating more measures would be helpful. Note also that though the shutters mitigate overheating using the static method in figure 2, for Case A during the heatwave, shutters are not enough to satisfy thermal comfort demand using the PMV method; however, adding the fan is necessary to do so.

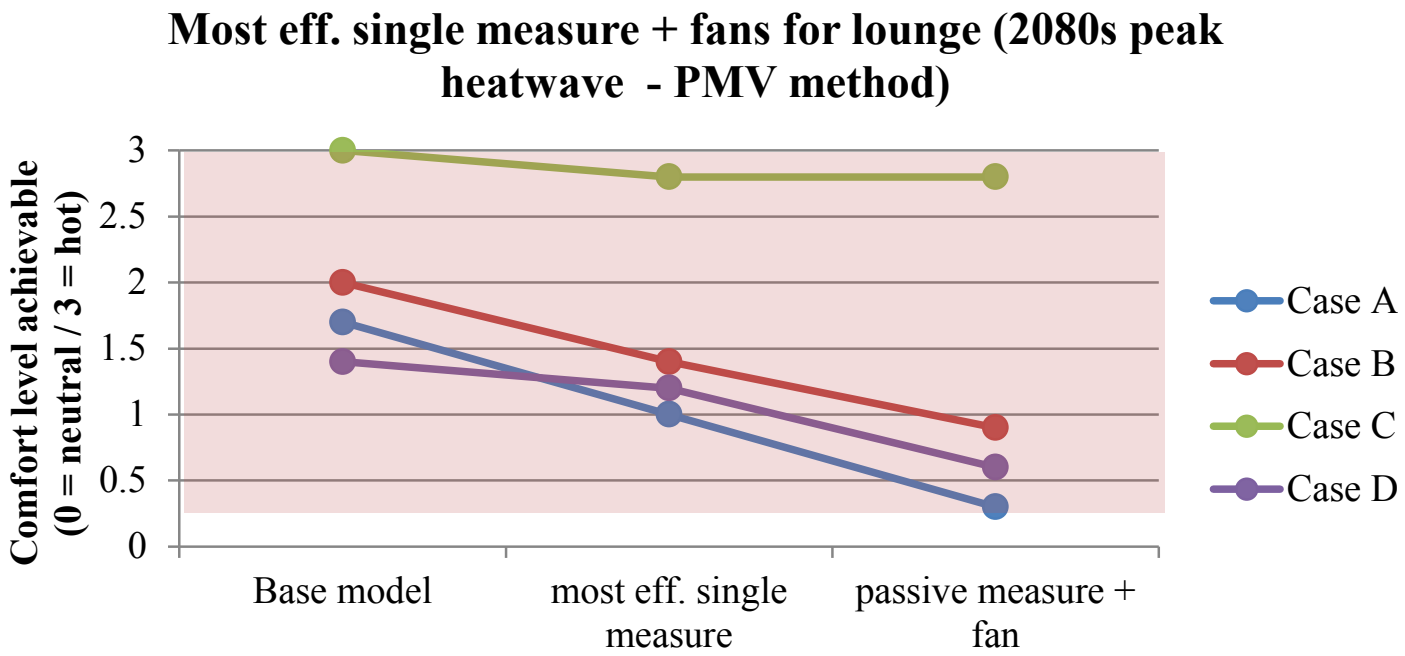

Figure 3. Most effective adaptation measures in combination with ceiling fans for the case studies' lounges.

Note: whereas the static method shown in the previous image indicates the impact on the seasonal overheating of the spaces, the PMV looks particularly at the impact of measures on the predicted thermal comfort of individuals during the peak temperatures of a heatwave in the selected climate period.

\section{Adaptation packages}

Figure 4 shows the impact of select adaptation measures and a 'full adaptation package' 
on the internal temperatures of a selected space during a heatwave period; table 5 shows the same for the overheating methods. The full adaptation package in the following example is comprised of exterior shutters, exposed thermal mass and managed natural ventilation.

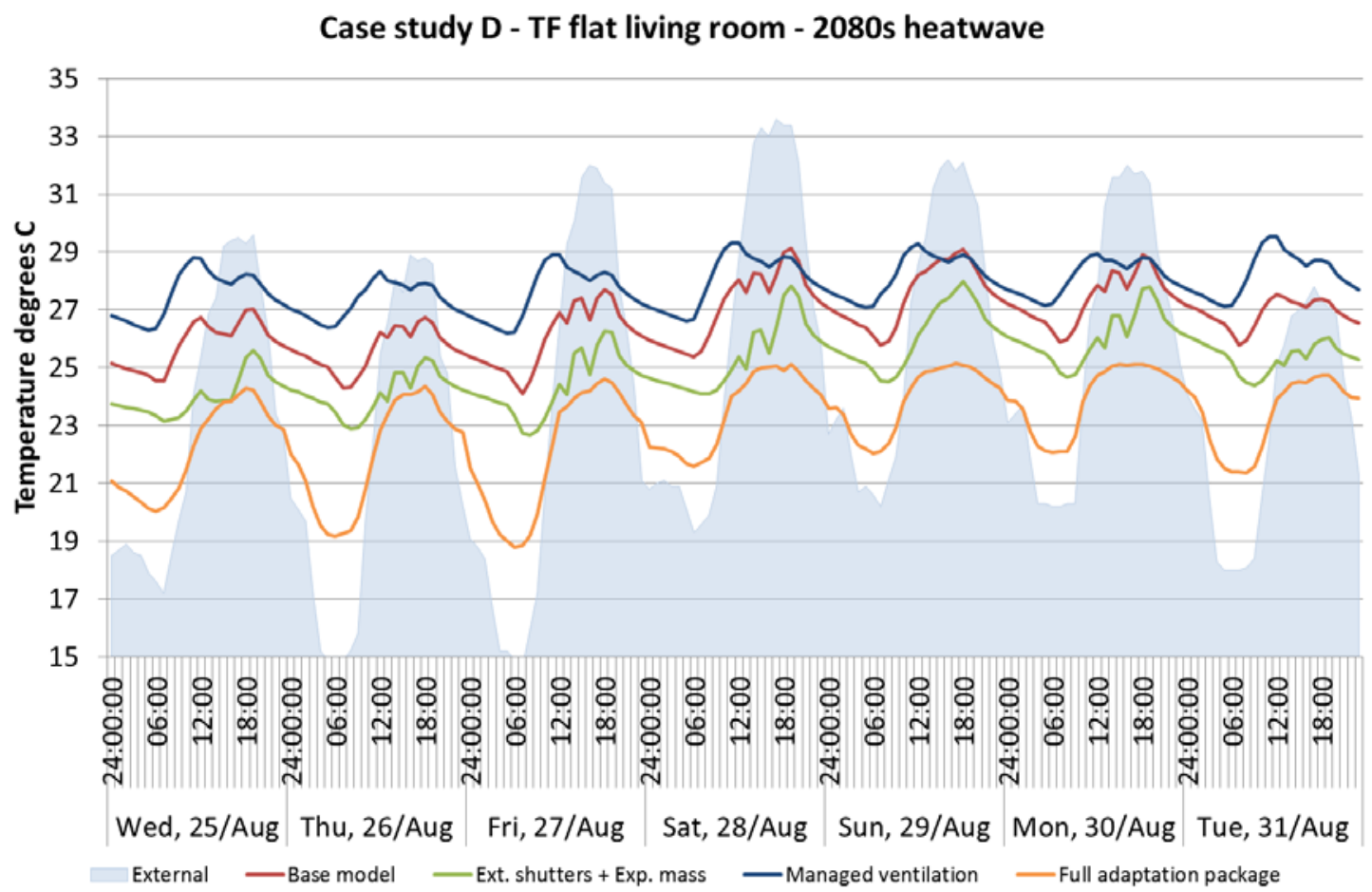

Figure 4. Third floor living room internal temperatures during a heatwave in the $2080 \mathrm{~s}$ climate period.

Table 5. Case D - third floor living room overheating results in the, 2080s

\begin{tabular}{|l|l|l|l|l|l|l|l|l|}
\hline \multirow{2}{*}{ 2080s high emissions } & \multicolumn{3}{|l|}{ TM52 Criterion Failed (AM) } & \multicolumn{3}{l|}{ CIBSE guide A (2006) (SM) } \\
\cline { 2 - 8 } & Base probability & Shutters & Man. & Full & Base & Shutters & Man. & Full \\
& model & & Vent. & package & model & & Vent. & package \\
\hline TF flat - living room & - & - & - & - & 2.7 & $-*$ & 5.4 & - \\
\hline
\end{tabular}

* Note: Package not necessary; exterior shutters sufficient as single measure to mitigate overheating risk; Man. Vent. = managed natural ventilation; .. Mass $=$ thermal mass

In this case, the most effective adaptation measures are external shutters, canopy cover, 
and green cover. This list suggests that the third floor (TF) flat is overheating as a result of too much incident solar gain. As can be seen in figure 4 and table 5, managed ventilation alone would be a hindrance to the TF flat, locking in gain and not allowing the temperature to drop internally to be ventilated. Note that though managed ventilation appears to be problematic as a singular measure, it is essential to the success of the full adaptation package to provide temperatures below $26^{\circ} \mathrm{C}$ during the heatwave. That is, if managed ventilation were removed from the full adaptation package, the external shutters and exposed thermal mass would be the result, i.e. far less effective than the full adaptation package (difference of $2.5^{\circ} \mathrm{C}$ during heatwaves in the $2080 \mathrm{~s}$ projection). In contrast to heatwave considerations, external shutters alone are sufficient in completely mitigating overheating risk.

To summarize the findings for the selected space presented, by 2030s no adaptation is needed, by 2050s it is suggested that ceiling fans are installed or no adaptation is needed, by 2080 s external shutters would be entirely sufficient to mitigate overheating; however, more action is needed to either bring down the internal temperature or cool the individual during a heatwave; therefore, either the full adaptation package or a shutters and ceiling fan package is recommended.

For all cases, the resultant suggested adaptation packages are marked in table 6 . The measures could be phased over time according to the FWY data; where temperature/ thermal comfort monitoring may prove a more immediate need, it may be suggested that measures (or even entire packages) are installed now, in a step-wise method, observing the impact over time. 
Table 6. Physical measure package recommendations.

\begin{tabular}{|c|c|c|c|c|c|c|c|c|c|c|}
\hline & \multirow[b]{2}{*}{ Room } & \multicolumn{7}{|l|}{ Passive } & \multirow{2}{*}{$\begin{array}{l}\text { Semi-active } \\
\text { Managed } \\
\text { natural } \\
\text { ventilation }\end{array}$} & \multirow{2}{*}{$\begin{array}{l}\text { Active } \\
\text { Ceiling fan }\end{array}$} \\
\hline & & $\begin{array}{l}\text { Draught } \\
\text { proofing }\end{array}$ & $\begin{array}{l}\text { Double } \\
\text { glazing (pref. } \\
\text { triple glazing) }\end{array}$ & $\begin{array}{l}\text { Blinds } \\
\text { (interior) }\end{array}$ & $\begin{array}{l}\text { Shutters } \\
\text { (exterior) }\end{array}$ & $\begin{array}{l}\text { Reflective ext. } \\
\text { wall } \\
\text { insulation }\end{array}$ & $\begin{array}{l}\text { Reflective } \\
\text { roof }\end{array}$ & $\begin{array}{l}\text { Exposed } \\
\text { thermal mass } \\
\text { (ceiling) }\end{array}$ & & \\
\hline \multirow{4}{*}{ 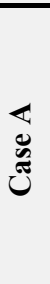 } & Lounge / Dining (FF) & & & $\checkmark \quad \rightarrow$ & $\checkmark$ & & & & & $\checkmark$ \\
\hline & $\begin{array}{l}\text { Manager's office } \\
\text { (GF) }\end{array}$ & & & $\checkmark \rightarrow$ & $\checkmark$ & & & & & $\checkmark$ \\
\hline & Bedroom 1 (GF) & & & & $\checkmark$ & & & & & $\checkmark$ \\
\hline & Bedroom 3 (FF) & & & $\checkmark \rightarrow$ & $\checkmark$ & & & & & $\checkmark$ \\
\hline \multirow{4}{*}{$\underset{0}{\mathscr{0}}$} & Lounge 2 (GF) & $\checkmark$ & $\checkmark$ & & $\bar{\checkmark}$ & $\checkmark$ & & & $\checkmark$ & $\bar{\checkmark}$ \\
\hline & S. Office (basement) & $\checkmark$ & $\checkmark$ & & & & & & $\checkmark$ & $\checkmark$ \\
\hline & Bedroom 1 (GF) & $\checkmark$ & $\checkmark$ & $\checkmark$ & & $\checkmark$ & & & $\checkmark$ & $\checkmark$ \\
\hline & Bedroom 3 (FF) & $\checkmark$ & $\checkmark$ & & $\checkmark$ & $\checkmark$ & & & $\checkmark$ & $\checkmark$ \\
\hline \multirow{5}{*}{ 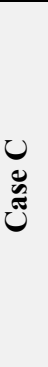 } & Lounge 1 (GF) & & & $\checkmark$ & & & $\checkmark$ & & $\checkmark$ & $\checkmark$ \\
\hline & $\begin{array}{l}\text { Manager's office } \\
\text { (GF) }\end{array}$ & & & & $\checkmark$ & & $\checkmark$ & & $\checkmark$ & $\checkmark$ \\
\hline & Flat 1 bedroom (GF) & & & & $\checkmark$ & & $\checkmark$ & & $\checkmark * *$ & $\checkmark$ \\
\hline & Flat 2 bedroom (FF) & & & & $\checkmark$ & & $\checkmark$ & & $\checkmark * *$ & $\checkmark$ \\
\hline & $\begin{array}{l}\text { Flat } 2 \text { living room } \\
\text { (FF) }\end{array}$ & & & & $\checkmark$ & & $\checkmark$ & & $\checkmark * *$ & $\checkmark$ \\
\hline \multirow{4}{*}{ 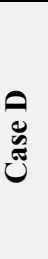 } & Lounge 1 (uGF) & & & & $\checkmark *$ & & & $\checkmark *$ & $\checkmark * * *$ & $\checkmark$ \\
\hline & Staff office (SF) & & & & $\checkmark *$ & & & $\checkmark *$ & & $\checkmark$ \\
\hline & Flat 1 bedroom (FF) & & & & & & & & $\checkmark$ & $\checkmark$ \\
\hline & $\begin{array}{l}\text { Flat } 1 \text { living room } \\
\text { (FF) }\end{array}$ & & & & & & & & $\checkmark$ & $\checkmark$ \\
\hline
\end{tabular}




\begin{tabular}{|l|l|l|l|l|l|l|l|l|}
\hline Flat 3 bedroom (TF) & & & & $\checkmark$ & & & & \\
\hline $\begin{array}{l}\text { Flat 3 living room } \\
\text { (TF) }\end{array}$ & & & & $\checkmark$ & & & & $\checkmark$ \\
\hline
\end{tabular}

Key: $\checkmark \rightarrow$ Blinds should progress to shutters in time

$\checkmark * \quad$ Either/or possibility

$\checkmark * *$ To be only used during heatwaves if implemented without full package

$\checkmark * * * \quad$ To only be used during heatwaves and at no other time. 


\section{Design interviews}

Interviews with design team shows that there appeared to be a general lack of awareness of the risks of climate change particularly related to overheating for care settings. In addition, designers were generally unaware of the formal Heatwave Plan for England guidance. As one interviewee stated, when designing and developing the briefing for care schemes, overheating is "the poor sister...to other aspects of climate change". Furthermore, planning for future overheating is not seen as a priority for care and housing providers who tend to focus on the near future rather than long term, e.g. the impact of climate change within the next 30 years or beyond. Whilst all interviewed considered designing for overheating to simply be 'good environmental design', one designer stated that, "We need to understand it a little bit more...we're (the industry as a whole) not as familiar with the solutions..." There was also an underlying attitude among both designers and managers that emphasised a culture of 'warmth'; cold is seen as the issue, and as such there was a focus in both the design and briefing documents for new schemes on provision of warmth, rather than a provision of cooling and/or adequate ventilation strategies.

Modelling and relevant overheating standards was an area of focus within the interviews. Interviewees commented on the fact that there is no clear definition or guidance on overheating to which designers can both design, and refer clients. There has been an increase in standards and guidance (such as CIBSE TM52 2013 and Building Regulations Part L2A 2013 (non-domestic but includes provision for domestic buildings that fall outside Part L1A such as care homes)) in terms of assessing the overheating risk in new buildings since all the case studies were constructed. However there is still no definitive regulatory requirement in the building sector. In addition, two out of the three design practices interviewed left the design of services, and modelling 
of thermal comfort with either environmental consultants, or mechanical and electrical (M\&E) engineers, which appears to have led to a lack of a joined-up approach between overall design of the care scheme buildings and services (heating, hot water, electrical systems) design.

\section{Discussion}

\section{Assessing the risk of and response to overheating}

The static method was found to be more sensitive to overheating throughout the results, meaning that more spaces overheated within a particular projection and at earlier projections using the static method. As the BWY DSY files do not indicate heatwaves or overheating in most cases this may suggest that the DSY weather year files for the current climate are not sufficient when designing for people of higher vulnerability to health risk.

Table 6 above demonstrates the findings of this study which can be summarized in the following considerations on how to apply adaptation measures to mitigate overheating:

(1) Adaptation measures may not be universally effective, i.e. many existing conditions of buildings cause the results to vary widely between buildings

(2) Measures may not be universally effective even at the building level, i.e. bedrooms can respond differently than offices, etc. Measures that mitigate overheating risk or enhance resilience will need to be tailored to each building's construction and location, and each individual space's orientation and occupancy pattern. 
(3) In some cases measures that are effective for long-term overheating (as assessed through either the adaptive or static methods) may not be effective during heatwaves and vice versa; therefore, design and adaptation should consider both overheating and heatwave risks as separate conditions.

These findings emphasize the importance of using dynamic thermal simulation, to evaluate the impact of future climate and to find the appropriate adaptation measures.

\section{Identifying influencing factors in overheating}

Building characteristics that contribute to overheating include: large proportion of exposed glazing (example: Case $\mathrm{C}$ lounge), building age, inadequate ventilation, high internal gains, location and orientation. The impact of the age of a building is most seen in the contrast between Case B and the other modern homes. Simply put, Case B overheats more than it should in a future climate due to being a leaky building with single glazing (as modelling the opposite conditions demonstrated improvement).

Modelling informed by case study observations demonstrate that inadequate ventilation of rooms (lack of window opening and closed trickle vents as observed during the building survey), increases the risk of overheating. Likewise, in a residential BPE study, combining supplemental ventilation and window ventilation particularly in kitchens was found to be important for reduction of overheating (QCHA and MEARU 2015). Also, in line with D4FC projects modelling found that single-sided ventilation (common to all case studies in this work and to the care sector in general) is significantly more prone to overheating as compared to cross-flow ventilation.

Often the design of the heating and ventilation systems is commissioned to M\&E services engineers and consultants, as in Case Study A where the architects were reliant on the consultants hired to undertake all the commissioning, testing and checking 
but who were not responsible for the handover of the building to the end-users. This can result in a lack of information provided to the end-users in how to operate systems, and subsequently a lack of knowledge within the end-users in how the systems work. Poor management of heating controls can result in localized heating being left on, e.g. in Case D each room has thermostatic control; the bathroom's control in a number of flats was discovered to be set to $30^{\circ} \mathrm{C}$ throughout the summer (with the main heating also on serving hot water supply). Though comparatively modelling both scenarios demonstrated a significant difference, the evaluation of adaptive responses assumed appropriate management of heating systems as a baseline.

The impact of location can vary greatly on overheating risk. To demonstrate an example of this, the Case A building was simulated in all four locations. Figure 5 shows the difference location plays in overheating potential for the 2080 s climate period. Bristol appears to present the highest overheating risk followed closely by Reading. This demonstrates that though Case $\mathrm{C}$ has a large glass to wall ratio which contributes to overheating, the climate in Bristol is also a significant contributor to consider. Interestingly, the slight difference between Reading and Bristol is reversed when assessing the results using the adaptive method; however, understanding why this 
difference exists is outside the scope of this study.

\section{Location tests - Case study A building - 2080s high emissions $50 \%$ probability - Static method}

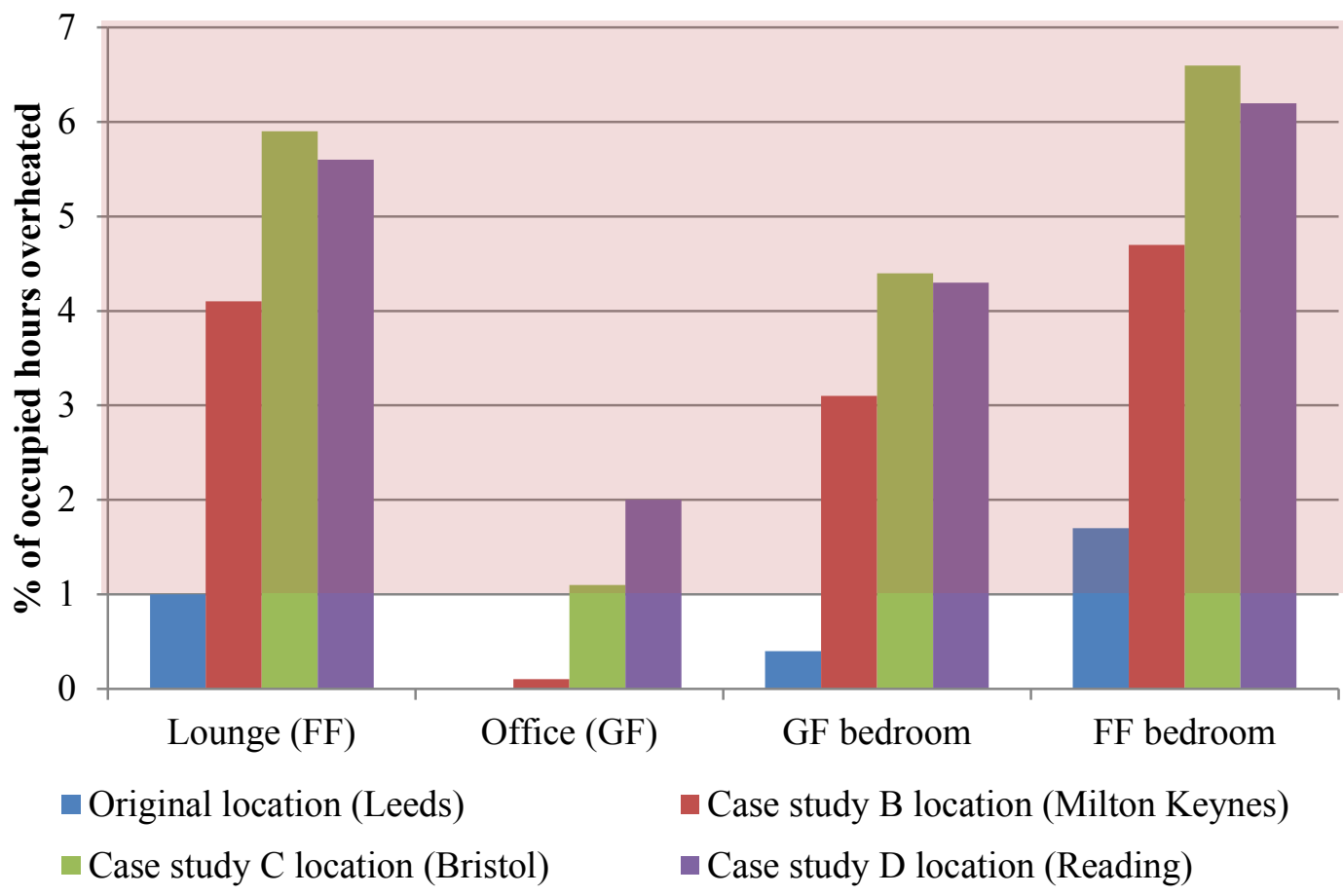

Figure 5. Location simulation results.

Overall, Case study A in NE England shows the least overheating. Location will impact significantly on need for overheating resilience as homes in the south of England will become more susceptible to overheating in future climate. For this reason it may be necessary to focus more immediate effort in the south of England. By the 2050s, passive strategies for tackling overheating will likely be necessary for all building types in the south of England. By 2080s, passive strategies for tackling overheating will likely be necessary for most locations and building types in the UK.

Orientation of certain spaces can also have an impact on overheating results in the way that the solar angles and wind direction can be embraced or shunned depending on need. For new construction, consideration of orientation is very important to programming a building where sustainability is seriously considered. Obviously in 
existing buildings, orientation can be difficult to change; however, if there is flexibility, understanding orientation can guide where to place certain individuals based on vulnerability or where to focus partial adaptive renovations if work must be phased over a long period. To demonstrate an example of this impact on overheating results, Case $\mathrm{C}$ was simulated in four additional orientations (figure 6). Table 7 shows the difference orientation plays on overheating potential for the 2080 s climate period. The only variable changed in the equation is orientation. This test demonstrates (as far as overheating risk is concerned) that:

- The lounge was correctly orientated (south) though it overheats significantly. This problem appears to have been understood from the beginning as the lounge has air conditioning installed.

- All other spaces would have benefited from northeast or north orientation.

- Bedrooms (spaces occupied at evening and night) would benefit from avoiding west (including southwest, northwest) orientations due to the late solar gain, whereas, spaces occupied during the daytime, e.g. offices and living rooms are more susceptible to overheating when facing southeast and east.
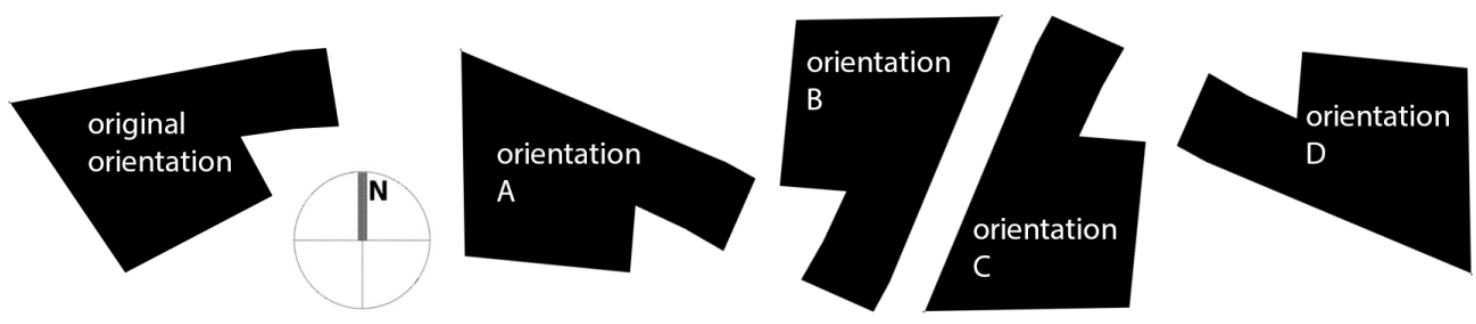

Figure 6. Orientation variations for Case C.

Table 7. Orientation change for Case $\mathrm{C}$ results.

\begin{tabular}{|l|l|l|l|l|l|}
\hline CIBSE guide A (2006) & Original & Orientation A & Orientation B & Orientation C & Orientation D \\
\hline
\end{tabular}




\begin{tabular}{|l|l|l|l|l|l|l|l|l|l|l|}
\hline (static method) & Face & $\mathbf{2 0 8 0}$ & Face & $\mathbf{2 0 8 0}$ & Face & $\mathbf{2 0 8 0}$ & Face & $\mathbf{2 0 8 0}$ & Face & $\mathbf{2 0 8 0}$ \\
\hline Lounge 1 (GF) & S & $\mathbf{6 . 6}$ & SW & +0.5 & NW & +0.5 & SE & +0.3 & NE & +0.1 \\
\hline Manager's office (GF) & SE & 4.7 & S & -0.4 & W & -0.2 & E & -0.6 & N & $\mathbf{- 0 . 8}$ \\
\hline Flat 1 bedroom (GF) & SW & 4.5 & W & -0.2 & N & $\mathbf{- 0 . 9}$ & S & -0.5 & E & -0.7 \\
\hline Flat 2 bedroom (FF) & E & $\mathbf{2 . 0}$ & SE & +0.1 & SW & +0.3 & NE & - & NW & +0.3 \\
\hline Flat 2 living room (FF) & E & 3.8 & SE & -0.3 & SW & -0.3 & NE & $-\mathbf{0 . 7}$ & NW & -0.3 \\
\hline
\end{tabular}

Note: Face = orientation of majority of glazing for a specific space; number under the climate period for orientations A through $D=$ change in percentage of overheating hours using the static method.

\section{Integration of physical adaptation measures with management and care}

\section{practices}

The most effective single passive measure across all case studies is external shading, i.e. shutters as modelled in the current project. In addition however, there is a need to build resilience in the care sector, to extend both awareness and understanding of heat-related risks for older people amongst all of those involved in the provision of care. Though the adaptation responses focussed primarily on physical change to the buildings, neither design or management/care changes are deemed sufficient responses on their own.

It is particularly important that internal heat gains are minimized during heatwaves. This is to ensure that the heating system is completely switched off, not just in terms of room temperature controls but any circulation of hot water through the heating system. Building surveys of the case studies found that heating systems were still on during hotter weather, in part this is suspected because of the general culture of 'fear of the cold' and potentially a readiness for unexpected cold weather, but also due to a lack of clarity as to whose role it is to be in charge of the heating system and its use. It follows that management should be proactive in understanding (or trusting the capability of technical staff to operate) the mechanical systems and how they should be 
operated seasonally. At both building and room level checks should be performed to avoid internal heat gain in summer.

As part of raising awareness about heatwaves and summertime thermal comfort more generally all staff should be educated about solar gain impact, internal gains from heating systems, and ventilation. This will require education on how to operate heating systems, shading devices (internal or external), and ventilation systems seasonally. Essentially, as an additional job task, care staff may be expected to operate shading elements (e.g. open shutters) and open and close windows for ventilation. This can be considered a part of caring for the resident as thermal comfort has an impact on health. For extra-care homes education can extend to the residents and their frequently visitors.

Finally, understanding orientation can guide where to place certain individuals based on vulnerability. As an example, north, east and northeast facing bedrooms were found to overheat less. More vulnerable or bed-bound residents should be placed in these bedrooms where less is required to reduce the overheating risk. It is however, understood that there are other factors limiting resident placement.

\section{Conclusion}

The study findings add important new evidence on the current and future risk of summertime overheating in care and extra-care settings in the UK. Such research is essential if adequate facilities are to be provided for the ageing and vulnerable population in the UK. The distinction and relation between heatwave conditions and being resilient to these, and more general patterns of overheating is not entirely straightforward, but ideally there should be complementarity between physical building related measures and those related to management and care practices.

Whilst significant heatwaves have been rare to date in the UK, this is projected to change; therefore, what is normally experienced is not a good guide to plan for what 
may come in the future. Being prepared for different future possibilities is important, just as is being prepared for the growth in the older population over coming decades. It is recommended that dynamic thermal simulation using future weather files (that incorporate short heatwaves) be required for assessing and tackling the current and future risk of summertime overheating in vulnerable settings such as care and extra-care homes through appropriate design, management and use.

The findings suggest that overheating is in some cases currently a potential risk or will be a risk, yet there is little awareness and implementation of suitable and longterm adaptation approaches such as external shading, provision of cross-ventilation. These strategies require input from designers, development teams, care providers, and all levels of care staff. Yet such fundamental change also requires support, in terms of enhanced and focused regulations, standards and guidance, from key care sector bodies and government departments or agencies. Care sector housing providers and designers need to consider the impact of heat on the health of residents and look beyond the tendency for near future planning to anticipate the effects on climate change. Whilst keeping older people warm is important for their health, the general culture of seeing 'cold' as dangerous, and warmth as good, can become a problem if it dominates the understanding of health risks as the climate changes. 


\section{Acknowledgements:}

We would like to thank the Joseph Rowntree Foundation for supporting this work. We wish to thank our academic partners, Dr Alan Lewis of the University of Manchester and Professor Gordon Walker and Dr Louis Neven of Lancaster University, and Laura Barnfield of Oxford Brookes University for their invaluable work and input into the study. We would also like to thank the architects, asset managers, care home staff and residents of the four case study buildings who helped with the data collection process. We are also grateful to those policymakers, practitioners and researchers who attended our workshop to discuss emerging findings and recommendations. 


\section{References:}

Åström, D. O., F. Bertil, R. Joacim. 2011. "Heatwave impact on morbidity and mortality in the elderly population: A review of recent studies." Maturitas 69 (2): 99-105. DOI: http://dx.doi.org/10.1016/j.maturitas.2011.03.008.

Barnes, S., J. Torrington, R. Darton, J. Holder, A. Lewis, K. McKee, A. Netten, and A. Orrell. 2012. "Does the design of extra-care housing meet the needs of the residents? A qualitative study." Ageing and Society 32: 1193-1214.

Brown, S. 2010. "In the Heat of Power: Understanding Vulnerability to Heatwaves in Care Homes for Older People.” PhD Thesis, Lancaster University.

Burns, A. 2008. "POE of Colliers Gardens in Bristol.” Report for Post-occupancy evaluation course, Oxford Brookes University.

Chartered Institution of Building Services Engineers (CIBSE). 2006. Environmental design, CIBSE guide A. London: CIBSE.

Chartered Institution of Building Services Engineers (CIBSE). 2013. The limits of thermal comfort: avoiding overheating in European Buildings. Technical Memorandum 52. London: CIBSE.

Chartered Institution of Building Services Engineers (CIBSE). 2015. Environmental design, CIBSE guide A. London: CIBSE.

Coley, D., T. Kershaw, and M. Eames. 2012. "A comparison of structural and behavioural adaptations to future proofing buildings against higher temperatures." Building and Environment 55: 159-166. DOI: http://dx.doi.org/10.1016/j.buildenv.2011.12.011.

Department for Environment, Food and Rural Affairs (Defra). 2012. UK Climate Change Risk Assessment: Government Report. London: HMSO.

Eames, M., T. Kershaw, and D. Coley. 2011. "On the creation of future probabilistic design weather years from UKCP09.” Building Services Engineering Research and Technology 32 (2): 127-142. DOI: 10.1177/0143624410379934.

EEA (European Environment Agency). 2012. “Observed global fossil fuel $\mathrm{CO}_{2}$ emissions compared with six scenarios from the IPCC." http://www.eea.europa.eu/data-and-maps/figures/observed-global-fossil-fuel-co2

Emerson Electric Company (EEC) 2015. "Eco Motor." http://ceilingfans.emerson.com/shop/en/fan/FAN-en-us-Pages-eco-ceiling-fans 
Flyvbjerg, B. 2006. "Five misunderstandings about case-study research." Qualitative Inquiry 12 (2): 219-245.

Fouillet, A., G. Rey, F. Laurent, G. Pavillon, S. Bellec, C. Guihenneuc- Jouyaux, J. Clavel, E. Jougla, and D. Hemon. 2006. "Excess mortality related to the August 2003 heatwave in France." International Archives of Occupational and Environmental Health. 80 (1): 16-24. DOI: 10.1007/s00420-006-0089-4

Gale, D., J. Fitzsimmon, T. Gartner, and M. Gale. 2011. "St. Loyes ExtraCare4Exeter: A report for the Technology Strategy Board." London: TSB.

Gasparrini, A., B. Armstrong, S. Kovats, and P. Wilkinson. 2012. "The effect of high temperatures on cause-specific mortality in England and Wales." Occupational and Environmental Medicine. 69 (1): 56-61. DOI:10.1136/oem.2010.059782.

Guerra Santin, O. and A. C. Tweed. 2013. "Summer post occupancy evaluation of a Passivhaus care home in the UK." Paper presented PLEA 2013 Sustainable Architecture for a Renewable Future, Munich, Germany, 10-13 September 2013. PLEA 2013 Munich: Sustainable Architecture for a Renewable Future.

Gupta, R. and M. Gregg. 2012. "Using UK climate change projections to adapt existing English homes for a warming climate." Building and Environment 55: 20-42. DOI: http://dx.doi.org/10.1016/j.buildenv.2012.01.014.

Gupta, R., M. Gregg, and K. Williams. 2015. "Cooling the UK housing stock post2050s." Building Services Engineering Research and Technology 36 (2): 196220. DOI: $10.1177 / 0143624414566242$.

Gupta, R., L. Barnfield, and M. Gregg. 2016. "Overheating in care settings: magnitude, causes, preparedness and remedies." Building Research \& Information (2016): 1-19. DOI: http://dx.doi.org/10.1080/09613218.2016.1227923.

Gupta, R. and M. Gregg. 2016. "Empirical evaluation of the energy and environmental performance of a sustainably-designed but under-utilised institutional building in the UK." Energy and Buildings 128 (2016): 68-80. DOI: http://dx.doi.org/10.1016/j.enbuild.2016.06.081.

Kenny, G. P., J. Yardley, C. Brown, R. J. Sigal, and O. Jay. 2010. "Heat stress in older individuals and patients with common chronic diseases." CMAJ : Canadian Medical Association Journal 182 (10), 1053-1060. DOI: http://doi.org/10.1503/cmaj.081050. 
Koppe, C., S. Kovats, G. Jendritzky, and B. Menne. 2004. "Health and Global Environmental Change - Series 2, No.2 - Heat-waves: Risks and Responses.” Denmark: World Health Organisation.

Kovats, R. S., H. Johnson, and C. Griffith. 2006. "Mortality in southern England during the 2003 heat wave by place of death.” Health Stat Quarterly 29 (3): 6-8.

Lewis, A. 2014. "Energy Use in an Ageing Society: The Challenges of Designing Energy-Efficient Older People's Housing.” Manchester Memoirs - Being The Memoirs and Proceedings of the Manchester Literary and Philosophical Society. 151: 20-32.

McHugh, I. and G. Keefe. 2012. "Adapting British Trimmings Extra Care Home in Leek, Final report for Design for Future Climate programme.”

Medical Architecture (MA) and Oxford Brookes University (OBU). 2012. "Edge Lane, Liverpool: Design for Future Climate Project.”

Met Office. 2015. Heat-health watch. http://www.metoffice.gov.uk/public/weather/heat-health/\#?tab=heatHealth

Neven, L., G. Walker, and S. Brown. 2015. "Sustainable Thermal Technologies: Productive Alignment or Risky Investment?” Energy Policy 84 (2015): 195-203. DOI: http://dx.doi.org/10.1016/j.enpol.2014.11.027.

Office for National Statistics (ONS). 2014. "National Population Projections, 2012Based Projections Release." http://www.ons.gov.uk/peoplepopulationandcommunity/populationandmigration /populationprojections/bulletins/nationalpopulationprojections/2013-11-06

Public Health England (PHE). 2014a. "Heatwave Plan for England - Making the case: the impact of heat on health - now and in the future." London: Department of Health.

Public Health England (PHE). 2014b. "Heatwave Plan for England: Protecting Health and Reducing Harm from severe heat and heatwaves." London: Department of Health.

Queens Cross Housing Association (QCHA) and Mackintosh Environmental Architecture Research Unit (MEARU). 2015. "Building Performance Evaluation study of Sheltered housing at Garscube Road in Glasgow, Final report for TSB's Building Performance Evaluation programme.” 
Rodrigues, L.T., M. Gillott, and D. Tetlow. 2013. "Summer overheating potential in a low-energy steel frame house in future climate scenarios." Sustainable Cities and Society 7 (2013): 1-15. DOI: http://dx.doi.org/10.1016/j.scs.2012.03.004.

UK Climate Projections (UKCP). 2012. "UK climate projections" http://ukclimateprojections.metoffice.gov.uk/

Walker, G., S. Brown, and L. Neven. 2015. "Thermal comfort in care homes: vulnerability, responsibility and 'thermal care'." Building Research and Information 44 (2): 135-146. DOI: http://dx.doi.org/10.1080/09613218.2014.998552. 